\title{
Identifying the Possibilities for Superior Recovery by Pelletization of Industry Related Small and Powdery Iron Containing Waste
}

\author{
Sorina Gabriela Șerban, Imre Kiss
}

University Politehnica Timişoara, Department of Engineering \& Management, Faculty of Engineering Hunedoara, 5, Revolutiei, Hunedoara, Romania e-mails: sorina.serban@fih.upt.ro,imre.kiss@fih.upt.ro

\begin{abstract}
Maximal recovery of iron contents waste is an important problem in siderurgy, since its needed transformation into by-products, thus into valuable economic goods, can lead to a rational exploitation of raw material, thus, ensuring industrial needs, as well as environmental protection. Powder waste can be processed in the form of pellets or briquettes and then is used in the steelmaking processes. Thus, the powdery ferrous wastes resulting from the materials industry, from the point of view of granulation, corresponds to processing by pelletization. In line with the superior recovery of waste, our research has focused on identifying the possibilities for the pelletization of industry related the small and powdery iron containing waste that exists in very large quantities, in Hunedoara County area (Hunedoara and Calan) and beyond. This article presents the results relating to the possibilities of pelletization, of industrial small and powdery iron containing waste, from the steel industry (steel dust, mixed agglomerating and blast furnace dust, landfilled in siderurgical ponds, in vicinity of the former industrial areas of Hunedoara and Calan, Hunedoara County). The origin of the material is the minerals (bauxite residue / red mud, landfilled in vicinity of Oradea, Bihor County) or from metal surface treatment operations (coating anticorrosive dust, collected in Oradea) in the industry. The waste utilized in the laboratory experiments was processed using a series of installed equipped in the laboratories at the Faculty of Engineering in Hunedoara, University Politehnica Timisoara.
\end{abstract}

Keywords: steel dust; mixed agglomeration and blast furnace dust; bauxite residue (red mud); anti-corrosive sludge; pelletizing process; experimental pellets; compression test

\section{Introduction}

In the production stream of steelmaking, steel operators generate iron containing waste, continuously, in appreciable quantities, proportional to their steel production [1-7]. The main small and powdery ferrous waste, with the reported iron content are: steel dust, agglomerate dust and sludge, blast furnace dust and 
sludge, converter dust and sludge, electrical steel mill electrofilter dust or a mixture of water with fine particles of material resulting from the mechanical preparation of ores or coal [7-13].

In addition to the ferrous waste resulting from the metallurgical industry, waste with ferrous content is also generated from other industries (mining and processing of minerals, energy sector, chemical industry, etc.), such as: pyritic ash from chemical industry, iron concentrate from thermal power plant ash, other waste such as lime dust, dolomite, bauxite residue (red mud), anti-corrosive sludge, galvanic sludge, etc. [1-6, 8-10].

Waste resulting from various technological processes, in particular those resulting from industrial metallurgical, mining or ore processing processes, can be processed by pelletization, briquetting and/or agglomeration, meaning that it can be used in the development of cast iron and steel production [7-26]. By processing this waste, as well as processing it into by-products, qualitatively suitable for use as raw materials or auxilliary materials in the steel industry, the areas currently occupied, can be rendered back to the surrounding landscape, thus, contributing to the greening of the general environment, as well as to the expansion of the raw material base $[1-10,13]$.

Pelletizing is an integral non-pressure agglomeration technique, in the mineral processing industry, that transforms various iron content materials into a premium by-products, a larger particles/agglomerates form "iron pellets", suitable for use in an iron-making furnace, at a steel mill, such as a blast furnace or electric arc furnace [7, 9-10, 13-26]. This processing transforms the small and powdery ferrous materials into a concentrated raw material suitable for pelletizing, as opposed to being disgarded. Such minerals or raw materials, that are commonly pelletized include [1-10,13]:

- Mined iron ore

- Other source of iron such as dust collected from blast furnaces, steel plants, convertors or agglomerating sectors

- Sludge collected from mine sites such as limestone, alumina, bauxite etc.

- Sludge collected from mineral processing sectors such as red mud, galvanising sludge, coating anticorrosive sludge etc.

In order to pelletize the small and powdery ferrous materials, a binder is needed, bentonite clay being a common choice [7, 9-10, 13-26]. Various additives may also be included with the feedstock to improve performance in the steel making (graphite, lime, dolomite etc.).

In general, three primary tehnological phases occur in any pelletizing process:

- The mixing process (Figure 1) - that sets the stage for creating a homogeneous mixture from the small and powdery raw materials that will allow for a uniform by-product (i.e. pellets) to be created. 
- The pelletizing (also named "balling") process, in which the agglomeration operations are made using a pelletizing equipment (or balling device). At this stage, the obtained balls are referred to as "green" pellets.

- The induration process (Figure 1) - which involves a thermal treatment that heats the "green" pellets to just before their melting point, causing them to become extremely hard. In fact, the "green" pellets will be fired in order to cure into their hardened form, as strong "fired" pellets.

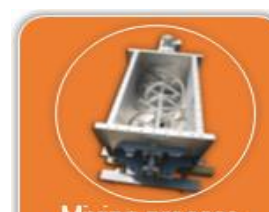

Mixing process

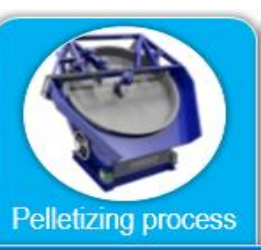

Pelletizing process

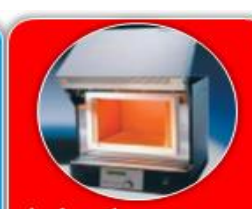

Induration process

Figure 1

The primary tehnological phases in any pelletizing process

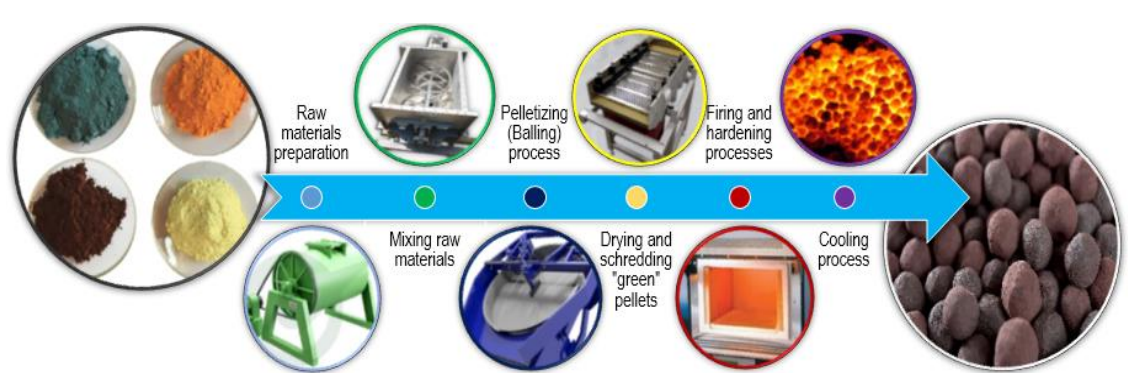

Figure 2

A complete pelletizing process
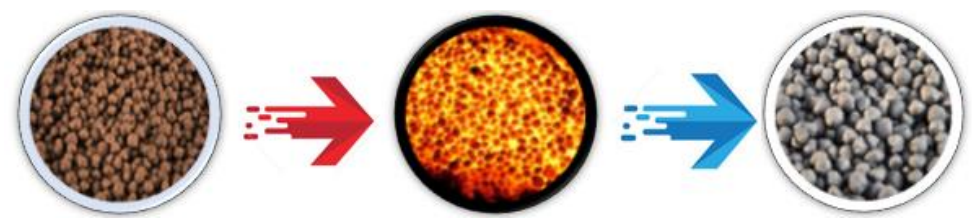

Figure 3

The by-products flow: "green" pellets - "fired" pellets - "cooled/hardened" pellets

A complete pelletizing process is typically comprised of a series of unit operations in a specific process sequence (Figure 2), in a generalized approach that can be divided into the following stages [7, 9-10, 13-26]:

- Stage of procurement and receiving raw material, the location of a pelletizing unit affecting the method of receiving raw materials such as fine and pulverous iron oxides content dust or sludge, additives and binders 
- Stage of pre-processing (pre-treatment process and preparation of raw materials), suitable for pelletizing (typically involves dry grounding into finer size and screening the pulverous materials)

- Stage of pre-wetting operation that includes adding an adequate amount of water homogeneously into the dry ground material to prepare pre-wetted material suitable for balling with optimum moisture.

- Stage of proportionating and mixing the components (main ferrous content wastes, additional ferrous content wastes) with other materials called binders and additives, creating a homogeneous mixture to prepare the green balls and to achieve the required quality in final by-product (i.e. iron oxide pellet).

- Stage of pelletizing on disc pelletizer (balling process) and producing the "green" pellets from the pre-wetted mixed material prepared in the previous operation (Figure 3).

- Stage of post-processing (mainly consisting in mechanical screening operations), the "green" balls produced on the disc pelletizer being not uniform in diameter, a significant portion of the discharge (about $70 \%$ ) being smaller (undersized) than target size and must be returned to disc pelletizer, after screening. If oversized balls are resulted (bigger than target size) will be returned to stage of pre-processing for dry grounding into finer size and re-mixing.

- Stage of indurating process (firing and hardening operations) the "green" pellets, establishing the binding of fine and pulverous particles at an elevated temperature, and producing the "fired" pellets (Figure 3). This is typically preceded by a drying stage, which may be carried out in the induration unit, or in a separate device, mainly in laboratory muffins furnace. After induration, the pellets can be cooled or left to cool.

- Stage of testing, often an essential part of the development of a successful pelletizing operation.

- Stage of handling of by-product (typically involves final screening for end user size requirements and storage).

\section{Quality of Pellets}

As a by-product, a typical iron pellet is roughly spherical in shape, measuring from $6 \mathrm{~mm}$ to $20 \mathrm{~mm}$ in diameter and having a minimum compression resistance in range of 180-200 daN/pellet or more, although some variations in these typical parameters can be specified and targeted in their preparation process [7, 9, 10, 13]. 
The quality of the pellets is influenced by the nature of the solid starting materials, the type and quantity of additions, the humidity of the mixture in the formation of "green" pellets and their hardening treatment [7, 10, 13]. Taking into account the demands to which pellets are subjected during transport, from the pelletization equipment to the elaboration aggregate, as well as the influence of temperature and transformations that take place in the processes of casting irons and steels manufacturing, it is necessary that they correspond to qualitative characteristics namely (chemical composition and optimal dimensions), as well as a good resistance to compression etc. [7, 10, 13].

Compression resistance is a factor of qualitative assessment of the pellets and is expressed in daN/pellet. Compression resistance is a feature that depends on the mineralogic composition of the used materials, the finesse of this material (the granulation), the addition of binder and additives, the working conditions applied and the size of the pellets $[7,10,13]$. For pellets with a diameter between 10 and $15 \mathrm{~mm}$ the minimum compression resistance must be in range of 180-200 daN/pellet.

Plasticity is also an important property of "green" pellets during their formation. The compression resistance of raw pellets is somewhat influenced by the plasticity of "green" pellets [7-13]. A certain degree of plasticity is required to support the growth rate of "green" pellets. If plasticity increases, the compression resistance of wet pellets decreases. The amount of moisture is required to create a certain degree of plasticity that depends on properties of particles and their distribution.

\section{Materials \& Methodology}

The wastes from mineral processing related sectors (bauxite residue/red mud, coating anticorrosive sludge), together with the wastes from siderurgy related sector (steel dust and the mix of agglomerating/furnace dust) were subjects of the pelletizing process, in presence of graphite, used as the reducing agent, respectively bentonite and lime, used as binders [7, 9-26].
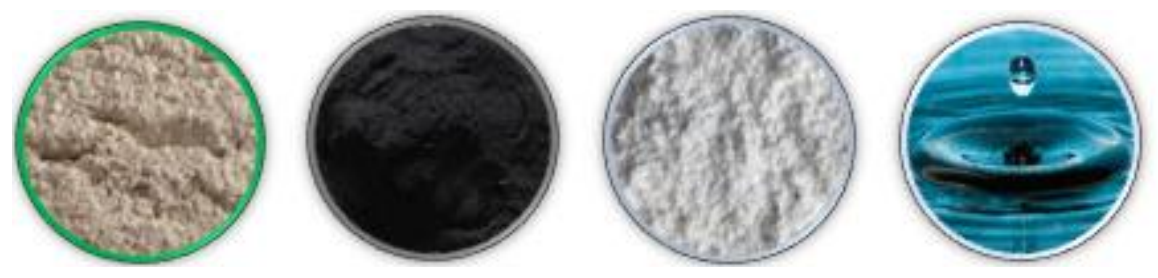

Figure 4

Main solid components: (a) steel dust / electric arc furnace dust, (b) blast furnace dust / agglomerating dust (mix), (c) bauxite residue / red mud, (d) coating sludge / anticorrosive sludge 

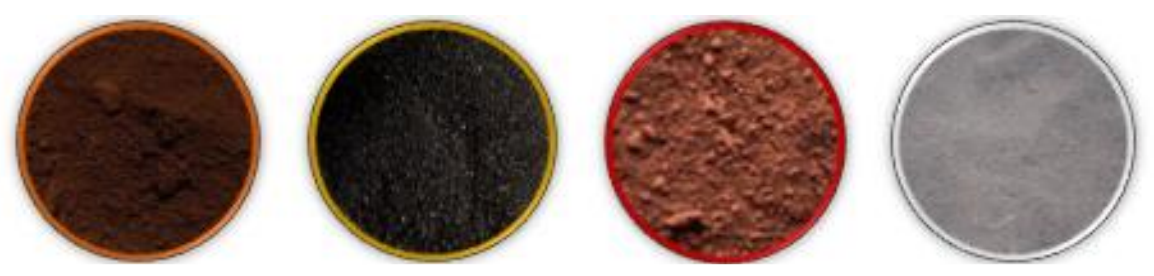

Figure 5

Binders, additives and water: (a) bentonite clay, (b) graphite powder, (c) hydrated-lime, (d) water

For the pellets production, the ferrous waste used (Figure 4) and the manufacturing formulations are shown in Table 1, which it also shows the proportions of bentonite and lime (experiment \#5 and \#6), used as binders (Fig. 5), as well as the proportion of graphite used as a reducer (experiment \#5 and \#6). For each formulation there were produced 4 series of pellets, so a total of 24 pelletization charges.

At preparation of the experimental recipes, we have in consideration the following preliminary remarks:

- The choice of waste was made according to its chemical and mineralogic composition. The purpose was to obtain the pellets by varying the amount of very fine waste, the binder content and the amount of water used. The binder was used to increase the resistance of the pellets, in laboratory experiments being used bentonite and lime [7, 10, 13]. The results are presented in Table 1.

- With the increase in the addition of bentonite and the proportion of fine fraction, the values for compression resistance also increase. Depending on the value of the compression resistance we want to obtain and the proportion of fine fraction in the pelletization shear we choose the addition of bentonite and water. Increasing the proportion of fine fraction in the pelletization shear, requires an increase in the addition of bentonite $[7,10$, 13].

- The recipes compositions and their percentual participation for the pelletizing charges in Table 1 and Figures 6-8 are presented.

The $1^{\text {st }}$ experimental experimental recipe is prepared with steel dust as main component $(72 \%)$, and equal percentages of red mud and anti-corrosive mud $(12 \%)$. This experimental recipe is prepared without agglomerating-furnace dust, graphite and lime, but is used $4 \%$ bentonite, as is presented in Table 1 and Figure 6 . The $2^{\text {nd }}$ experimental recipe is prepared with agglomerating-furnace dust as main component $(72 \%)$, and equal percentages of red mud and anti-corrosive mud $(12 \%)$. This experimental recipe is prepared without steel dust, graphite and lime, but is used same $4 \%$ bentonite (Table 1 and Figure 6). 
Table 1

Participation of solid components in experiments / recipes

\begin{tabular}{|l|l|l|l|l|l|l|}
\hline \multirow{2}{*}{ Components } & \multicolumn{6}{l|}{ Participation in experiments / recipes, [\%] } \\
\cline { 2 - 7 } & $\begin{array}{l}\text { Sample } \\
\# 1\end{array}$ & $\begin{array}{l}\text { Sample } \\
\# 2\end{array}$ & $\begin{array}{l}\text { Sample } \\
\# 3\end{array}$ & $\begin{array}{l}\text { Sample } \\
\# 4\end{array}$ & $\begin{array}{l}\text { Sample } \\
\# 5\end{array}$ & $\begin{array}{l}\text { Sample } \\
\# 6\end{array}$ \\
\hline Steel dust & 72 & 0 & 72 & 0 & 70 & 0 \\
\hline Agglomerating/ furnace dust & 0 & 72 & 0 & 72 & 0 & 70 \\
\hline Bauxite residue (red mud) & 12 & 12 & 24 & 0 & 0 & 24 \\
\hline Anti-corrosive protection mud & 12 & 12 & 0 & 24 & 24 & 0 \\
\hline Graphite & 0 & 0 & 0 & 0 & 1 & 1 \\
\hline Bentonite & 4 & 4 & 4 & 4 & 3 & 3 \\
\hline Lime & 0 & 0 & 0 & 0 & 2 & 2 \\
\hline
\end{tabular}
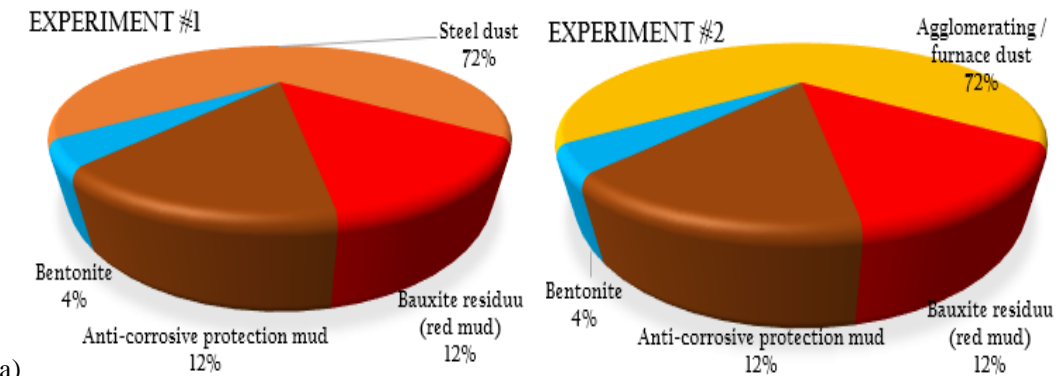

(a) $12 \%$

Figure 6

Participation (percentage) of solid components in Recipe\#1 (a) and in Recipe \#2 (b)
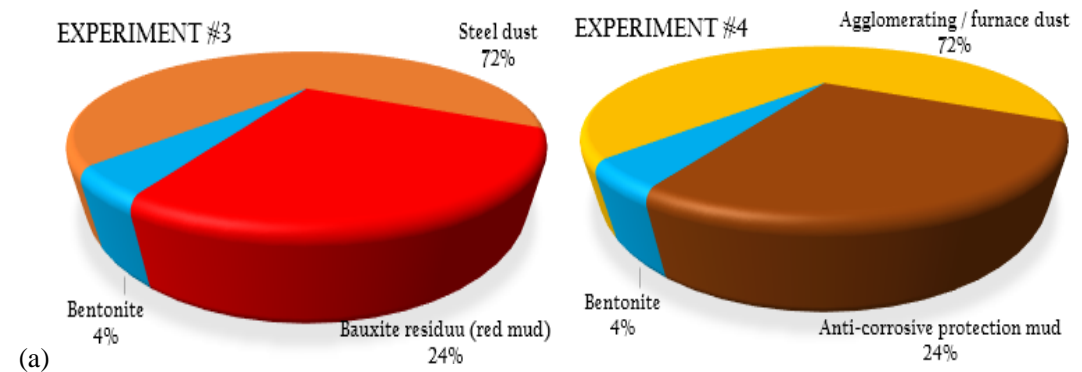

(b)

Figure 7

Participation (percentage) of solid components in Recipe \#3 (a) and in Recipe \#4 (b)

The $3^{\text {rd }}$ experimental recipe is prepared with steel dust as main component (72\%) and red mud (24\%). This recipe is prepared without agglomerating-furnace dust, anti-corrosive mud, graphite and lime, but is used the same $4 \%$ bentonite (Table 1 and Figure 7). The $4^{\text {th }}$ recipe is prepared with agglomerating-furnace dust as main component $(72 \%)$ and anti-corrosive mud (24\%). This experimental recipe is prepared without steel dust, red mud, graphite and lime, but is used the same $4 \%$ bentonite (Table 1 and Figure 7). 

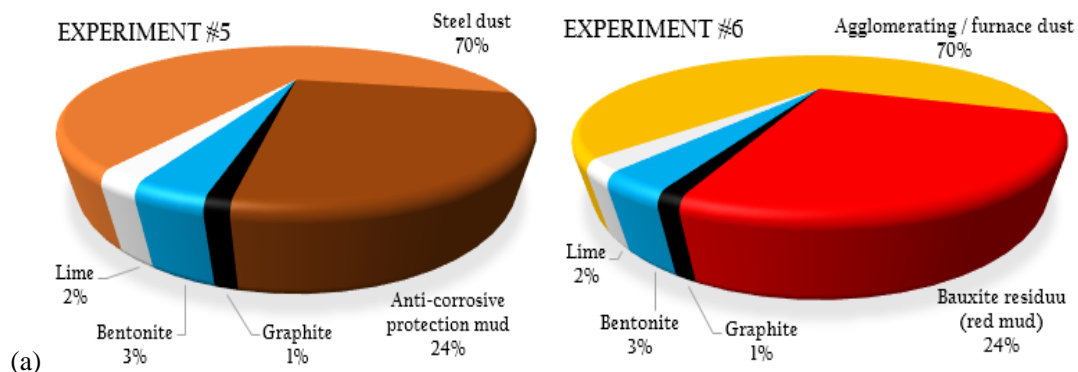

(b)

Figure 8

Participation (percentage) of solid components in Recipe \#5 (a) and in Recipe \#6 (b)

The $5^{\text {th }}$ experimental recipe is prepared with steel dust as main component (70\%) and anti-corrosive mud (24\%). This recipe is prepared without agglomeratingfurnace dust and red mud, but graphite (1\%), lime (2\%) and bentonite (3\%) are used (Table 1 and Figure 8 ). The $6^{\text {th }}$ experimental recipe is prepared with agglomerating-furnace dust as main component $(70 \%)$ and red mud $(24 \%)$. This recipe is prepared without steel dust and anti-corrosive mud, but graphite (1\%), lime (2\%) and bentonite (3\%) are used (Table 1 and Figure 8).

In our research, laboratory and pilot tests were carried out on the possibilities of recovery of pulverous ferrous waste in the form of pellets [7, 10, 13]. The influence of granulation and the weight of materials of different granulometric classes in the the pelletization recipe, the proportion of binder and the addition of water on the compression resistance of "green" and "hardened" pellet was studied [7-26]. The waste envisaged in the laboratory experiments was processed, according to the technological flow shown in Figure 2.

After homogenisation (mixing the solid components), the material (40 kg material/recipe) is inserted into the experimental equipment which is a disk pelletizer that belongs to the Laboratory of Materials Processing, in Faculty of Engineering Hunedoara [7, 9-26]. The pelletizing equipment (or "balling" device) used is a disc pelletizer, for production of balls (pellets), consist of an inclined, rotating disc mounted on a stationary structure. Nucleation, compaction, size enlargement, and spheroidization of the pellets ("balling" process) take place in the course of balling and related agglomeration processes [7, 9-26].

The duration of the pelletization process is range of 10-20 min. Throughout the process, the way of wetting the composition and the formation of the pellet ("balling") is followed. It was intended to determine the optimal additions of bentonite and water in order to obtain the most compression-resistant pellets. Depending on the humidity of the material, the water flow is adjusted. Balling has proved to be a highly versatile technique for large-scale production of particulate spheroids at relatively low capital and operational costs. Once pellets reach the desired size, they exit the pelletizing device [7, 9-26]. 

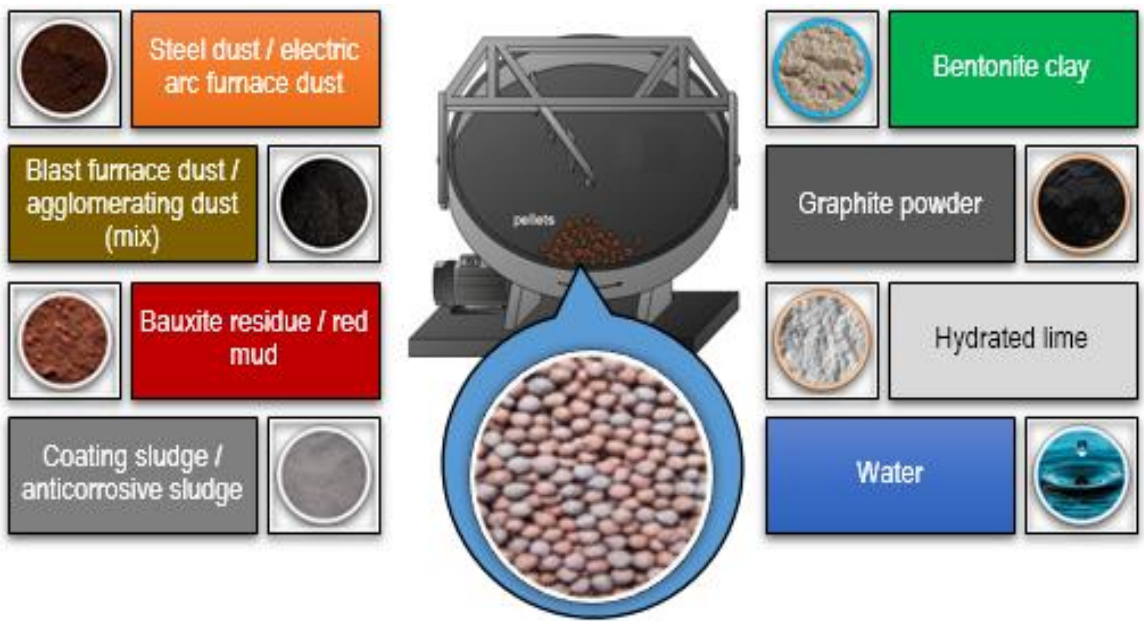

Figure 9

The pelletizing equipment and the "ingredients"

The waste used in the pelletisation process must have a fine granulation in order to form the proper pellet. For the obtained pellets, dusty wastes were used, their granulometric classes being presented in Table 2. Experimentally it was established that the size of the pellets was between 10 and $25 \mathrm{~mm}$. The dimensions of $10-15 \mathrm{~mm}$, a fraction representing at least $80 \%$ of the experimental recipes, were also considered to be optimal [7, 10, 13]. After completion of the pelletization operation, the obtained pellets are subjected to the granulometric sorting operation. The fraction less than $10 \mathrm{~mm}$, is reintroduced into the circuit (in the pelletization stream) and the fraction greater than $10 \mathrm{~mm}$ will be subjected to hardening process [7, 9-26].

Table 2

Characteristics of pelletizing process and pellets

\begin{tabular}{|c|c|c|c|c|c|c|c|c|c|}
\hline \multirow[b]{2}{*}{ 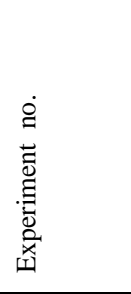 } & \multirow{2}{*}{ 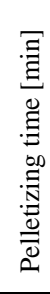 } & \multirow{2}{*}{ 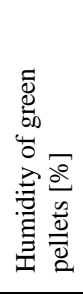 } & \multirow{2}{*}{ 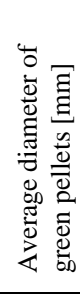 } & \multicolumn{5}{|c|}{$\begin{array}{l}\text { Granulometric classes proportion in the } \\
\text { experimental recipes [\%] }\end{array}$} & \multirow{2}{*}{ 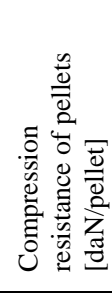 } \\
\hline & & & & 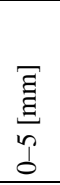 & $\begin{array}{l}\bar{\Xi} \\
\underline{\Xi} \\
0 \\
n \\
n\end{array}$ & $\begin{array}{l}\bar{\Xi} \\
\underline{\Xi} \\
\underline{o} \\
\underline{\varrho}\end{array}$ & 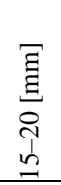 & 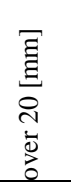 & \\
\hline Sample \#1 & 13 & 10.23 & 12.42 & 4 & 10.8 & 82.12 & 1.88 & 1.08 & 194 \\
\hline Sample \#2 & 14 & 9.78 & 12.66 & 4.12 & 10.41 & 83.34 & 1.76 & 0.37 & 179.5 \\
\hline Sample \#3 & 15 & 8.68 & 11.47 & 2.77 & 11.79 & 82.44 & 2.55 & 0.45 & 205 \\
\hline Sample \#4 & 16 & 9.34 & 14.23 & 3.8 & 12.34 & 80.14 & 3.76 & 0.38 & 210.5 \\
\hline Sample \#5 & 14 & 9.67 & 10.31 & 3.65 & 10.3 & 82.64 & 2.83 & 0.56 & 178 \\
\hline Sample \#6 & 13 & 10.25 & 10.23 & 4.21 & 13.78 & 80.25 & 1.78 & 0.78 & 178.5 \\
\hline
\end{tabular}


The hardening of the pellets are made by burning [7, 9-10, 13-26]. Burning hardening is done in electric (resistance) or flame ovens, following a proper treatment diagram (heating - maintenance - cooling), established on the basis of its own experiments (heating at $1150{ }^{\circ} \mathrm{C}$, for 2 hours, maintenance 30 minutes and cooling in the air).

After hardening, qualitative characteristics (chemical composition, dimensional analysis) and a mechanical characteristic (compression resistance of burned pellets) were determined in our laboratories. Also, the pellets are re-examined by the granulometric sorting operation, the fraction greater than $10 \mathrm{~mm}$ being dispatched to the beneficiary and the fraction less than $10 \mathrm{~mm}$ is recirculated (reintroduced into a new pelletisation circuit) [7, 10, 13-26].

\section{The Experimental Results}

We start to discuss by following the graphs from the Figures 10-12, which although conclusive, are not suggestive, because it presents a cumulative analysis of all factors that compete to achieve high quality pellets, i.e. the granulation of mixed components, humidity and the duration of pelletization:

- In making the recipes it was ensured that $80 \%$ of the solid components had a grain of 10-15 mm (Figure 10, according to Table 2)

- The duration of the pelletization operation, in the average of the 4 tests/recipe, was between 13-16 minutes (Figure 11, according to Table 2), which means a good time for such processes

- Diameters obtained for pellets, in a „green” state, are between 10-15 mm (Figure 11, according to Table 2)

- The necessary humidity for the plasticity of the „green” pellets was ensured at $8-11 \%$ proportions, relative to the volume of solid quantities (Figure 11, according to Table 2)

- At first view, the compression resistance that ensure sufficient quality of the pellets are obtained with formulations \#1, \#3 and \#4, being over 200 daN/pellet (Figure 12, according to Table 2). The other recipes provide a lower limit of quality requirements (180-200 daN/pellet). It is considered in the assessments that in most cases the pellets are intended for use in steelmaking aggregates. 


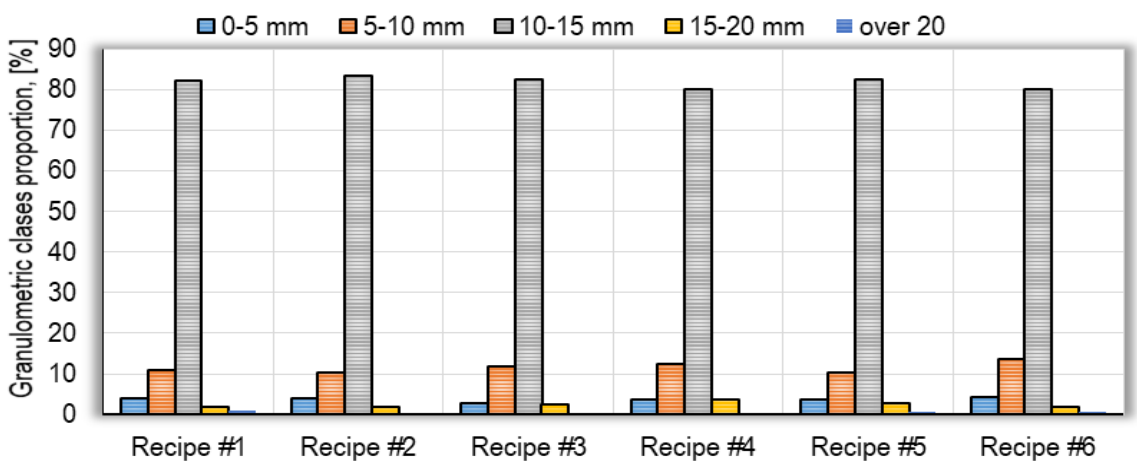

Figure 10

Granulometric classes proportion in the experimental recipes

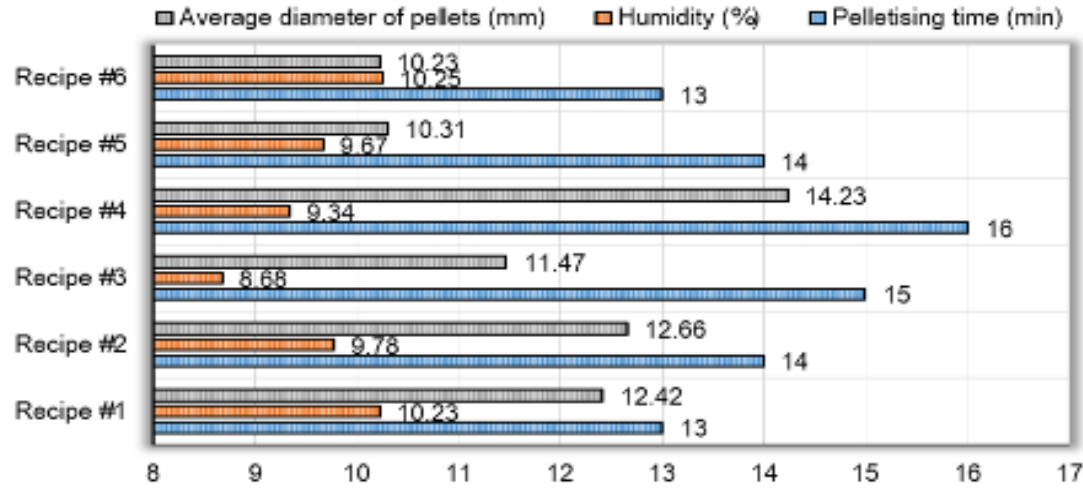

Figure 11

Average diameter of "green" pellets, humidity of "green" pellets and the pelletising time

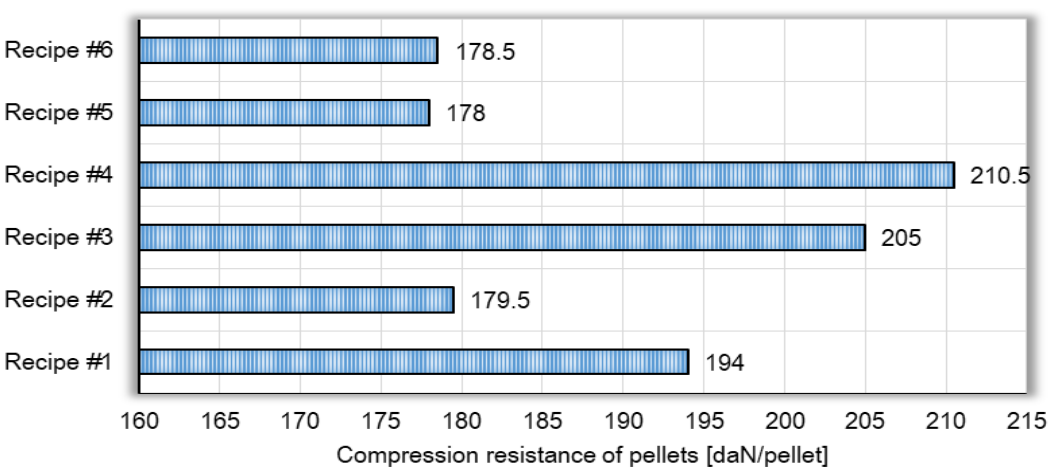

Figure 12

The compression resistance of the harnened pellets 


\section{Analysis and Discussion}

Our analysis of the study of the influence of solid components with iron content (steel dust, agglomeration-furnace dust, red mud/bauxide residue and anticorrosive sludge) on compression resistance, are graphically represented in Figures 13-17, based on the results obtained in our experiments.

In diagram presented in Figure $13,[\mathrm{Rc}=\mathrm{f}$ (steel dust, agglomeration-furnace dust)], it is noted that there is an area with a maximum point, and the range with values greater than $180 \mathrm{daN} /$ pellet is quite extensive, so that the variation limits for the two components are quite high (approximately 60 agglomeration-furnace dust, over $70 \%$ steel dust). It is noted that only at low values of the two components (approximately 60\% agglomeration-furnace dust, or over $70 \%$ steel dust), the resistance to compression is less than 180 daN/pellet. However, at values of only $40 \%$ agglomeration-furnace dust and between $30-60 \%$ steel dust, compression resistance reaches values of almost $200 \mathrm{daN} /$ pellet.

In the diagram presented in Figure $14,[\mathrm{Rc}=\mathrm{f}$ (steel dust, bauxide residue)], it is found that there is an increase in compression resistance with an increase in the proportion of red mud/bauxide residue and steel dust, the best values being obtained for the upper limits of the two components of the recipe. The technological explanation lies in the high finesse of both materials and the content of $\mathrm{Al}_{2} \mathrm{O}_{3}$ in bauxide residue. Depending on the availability of waste assortments it would be preferable to place their proportion at quantities that provide compression resistance above $200 \mathrm{daN} /$ pellet - in the right corner, top of the diagram (10-14\% bauxide residue and $30-70 \%$ steel dust) or more than 180 $190 \mathrm{daN} /$ pellet (10-14\% bauxide residue and between 10-70\% steel dust).

The diagram presented in Figure 15 [ $\mathrm{Rc}=\mathrm{f}$ (agglomeration-furnace dust, bauxide residue] shows the positive influence of bauxide residue, practically an addition of this between $4-16 \%$ ensures good values for the compression resistance of the pellets, even if the content of agglomeration-furnace dust does not exceed $50 \%$. Good values of compression resistance are also obtained for the level curves corresponding to some participations in recipes with 10-50\% agglomeration powder-furnaces and smaller amounts of bauxide residue (2-6\%).

In the case of use of anti-corrosive sludge together with agglomeration-furnace dust - Figure 16 [Rc $=\mathrm{f}($ agglomeration-furnace dust, anti-corrosive sludge $)]-$, it is found that higher values for compression resistance are obtained at their lower proportions in the pelletization charge. Very good quality pellets can be obtained with agglomeration-furnace dust within a maximum of 50\% and for 10-15\% anticorrosive sludge, or even lower (5-10\%). 


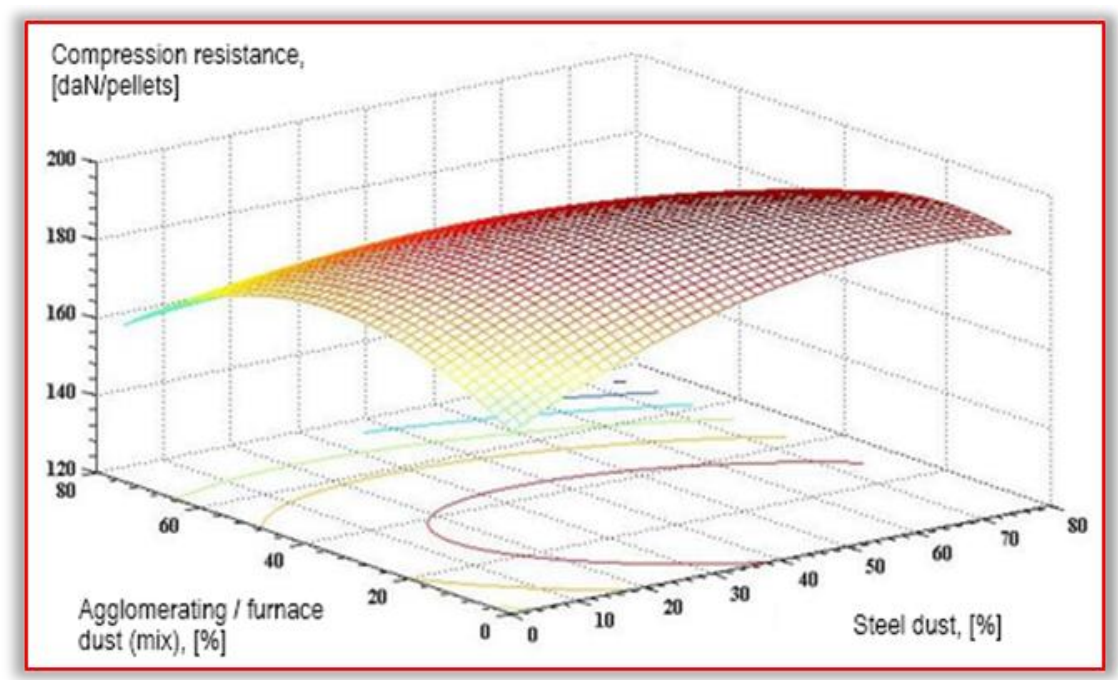

(a) the regression surface described by the laboratory data

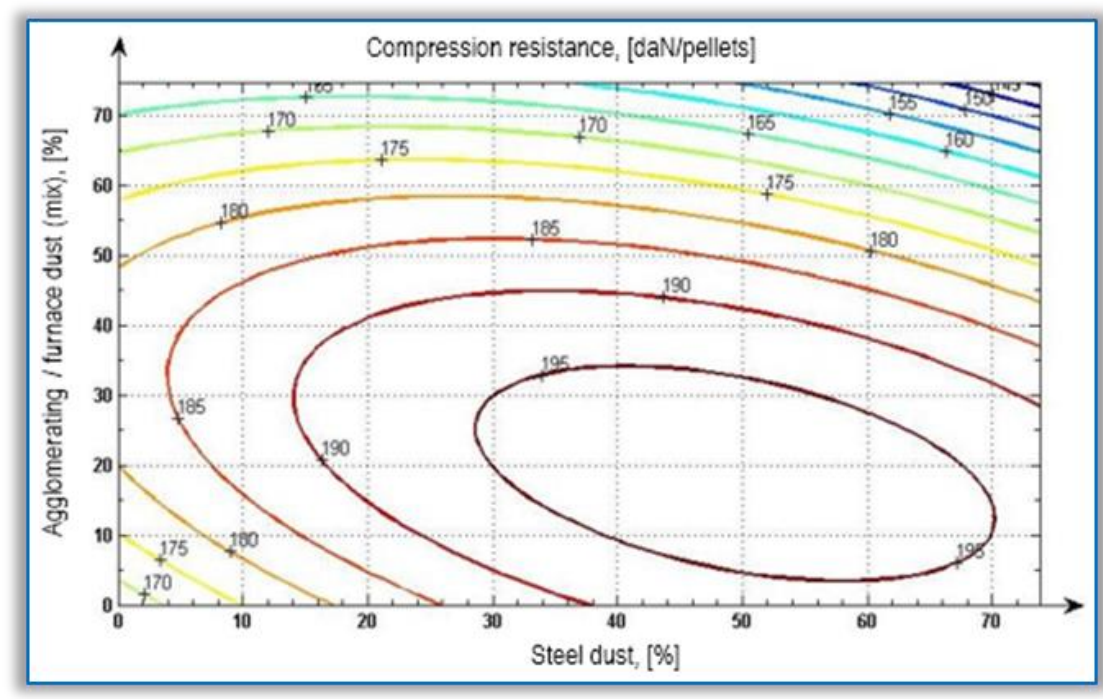

(b) the level curves of compression resistance, in 2D coordinates

Figure 13

Compression resistance of hardened pellet's with the proportions of agglomeration-furnace dust and steel dust used in the experimental recipes $-[\mathrm{Rc}=\mathrm{f}$ (agglomeration-furnace dust, steel dust $)]$

Equation type: $z=a_{(1)} x^{2}+a_{(2)} y^{2}+a_{(3)} x y+a_{(4)} x+a_{(5)} y+a_{(6)}$, in which the coefficients are: $\mathrm{a}_{(1)}=-0.0074 ; \mathrm{a}_{(2)}=-0.0137 ; \mathrm{a}_{(3)}=-0.0085 ; \mathrm{a}_{(4)}=0.8945 ; \mathrm{a}_{(5)}=0.9330 ; \mathrm{a}_{(6)}=166.7903$

Coefficient of multiple correlation: $\mathrm{R}^{2}=0.7482$ (relative high grade of correlation) 


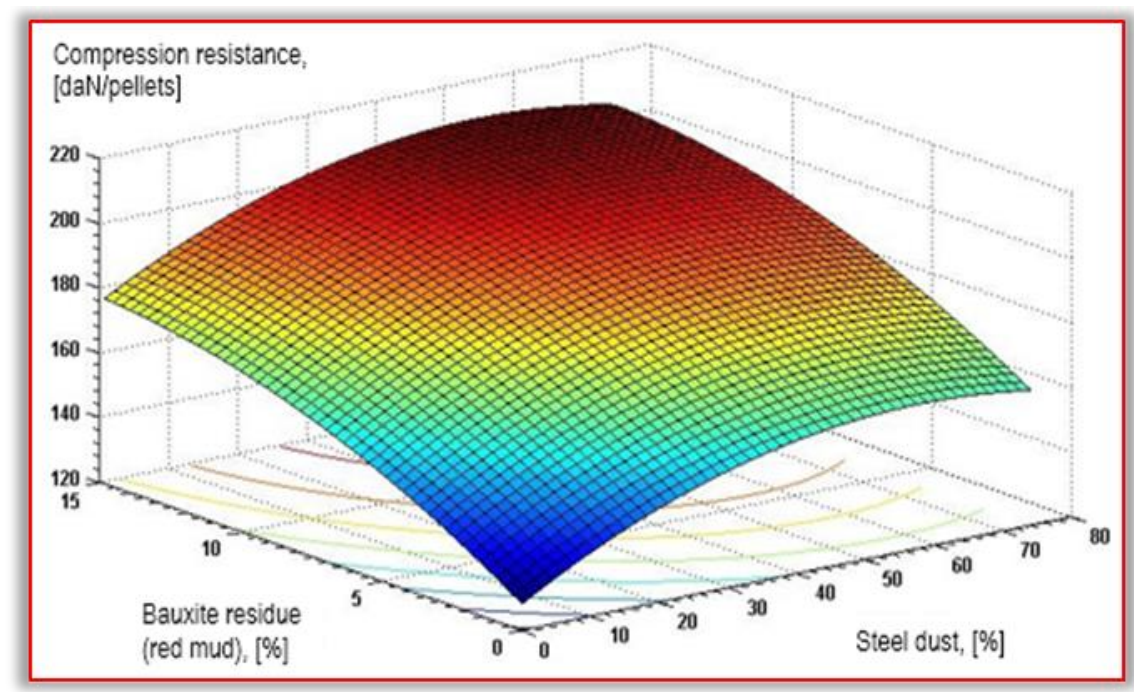

(a) the regression surface described by the laboratory data

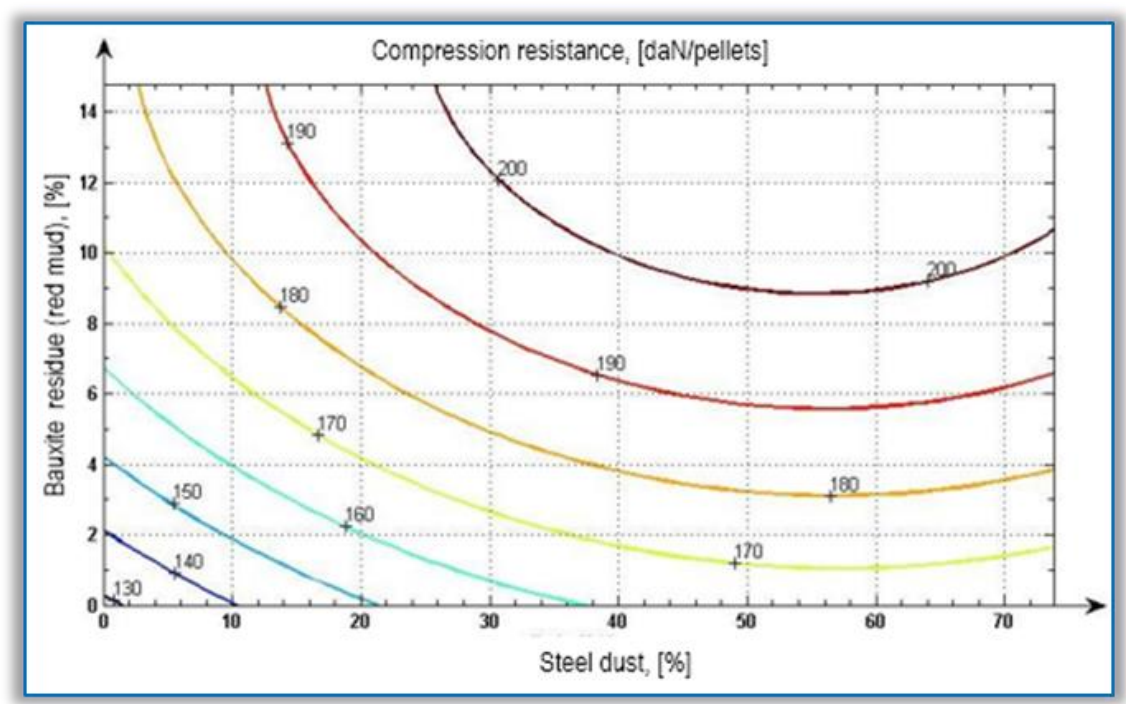

(b) the level curves of compression resistance, in 2D coordinates

Figure 14

Compression resistance of hardened pellet's with the proportions of steel dust and bauxite residue / red mud used in the experimental recipes $-[\mathrm{Rc}=\mathrm{f}($ steel dust, bauxite residue / red mud $)]$

Equation type: $z=a_{(1)} x^{2}+a_{(2)} y^{2}+a_{(3)} x y+a_{(4)} x+a_{(5)} y+a_{(6)}$, in which the coefficients are: $\mathrm{a}_{(1)}=-0.0109 ; \mathrm{a}_{(2)}=-0.1750 ; \mathrm{a}_{(3)}=-0.0055 ; \mathrm{a}_{(4)}=1.2592 ; \mathrm{a}_{(5)}=5.8883 ; \mathrm{a}_{(6)}=128.1288$

Coefficient of multiple correlation: $\mathrm{R}^{2}=0.9389$ (high grade of correlation) 


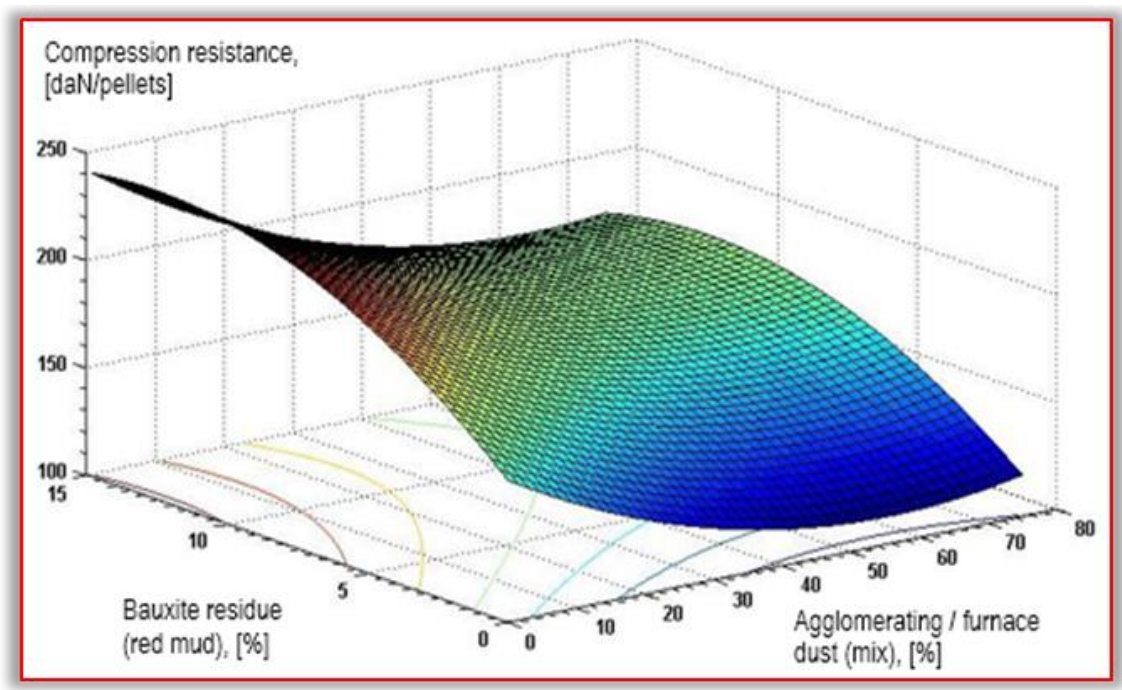

(a) the regression surface described by the laboratory data

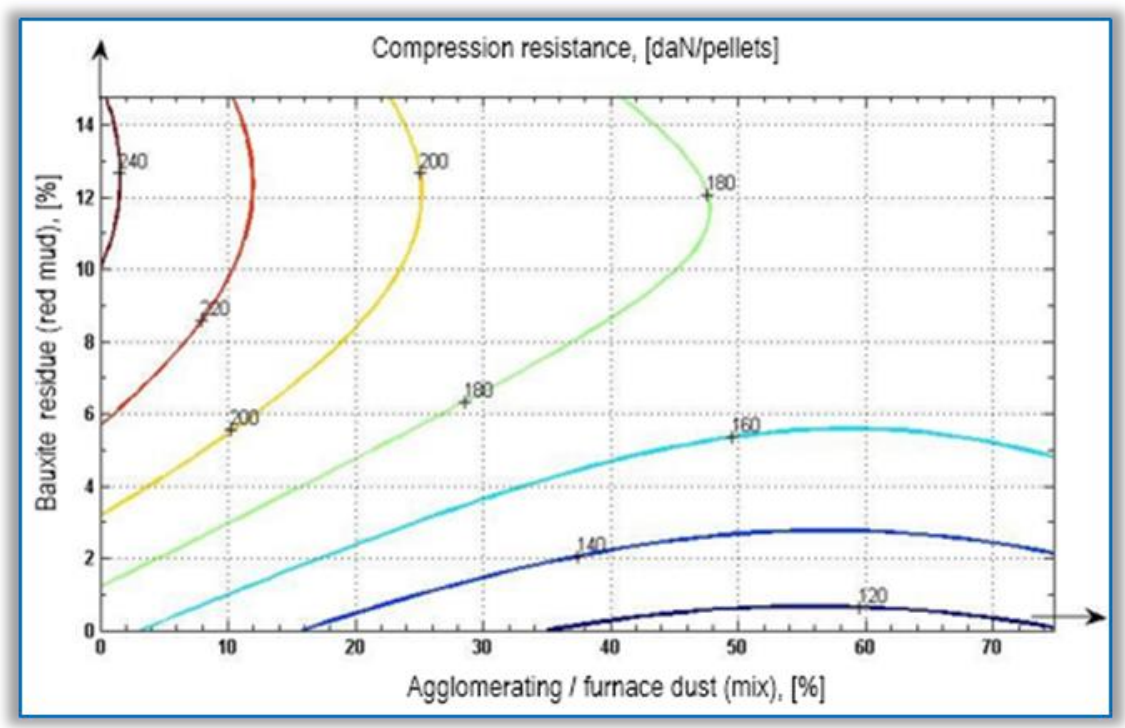

(b) the level curves of compression resistance, in 2D coordinates

Figure 15

Compression resistance of hardened pellet's with the proportions of agglomeration-furnace dust and bauxite residue used in recipes $-[\mathrm{Rc}=\mathrm{f}$ (agglomeration-furnace dust, bauxite residue) $]$ Equation type: $z=a_{(1)} x^{2}+a_{(2)} y^{2}+a_{(3)} x y+a_{(4)} x+a_{(5)} y+a_{(6)}$, in which the coefficients are: $\mathrm{a}_{(1)}=0.0173 ; \mathrm{a}_{(2)}=-0.4860 ; \mathrm{a}_{(3)}=-0.0193 ; \mathrm{a}_{(4)}=-1.9154 ; \mathrm{a}_{(5)}=12.2658 ; \mathrm{a}_{(6)}=165.8485$ Coefficient of multiple correlation: $\mathrm{R}^{2}=0.8652$ (high grade of correlation) 


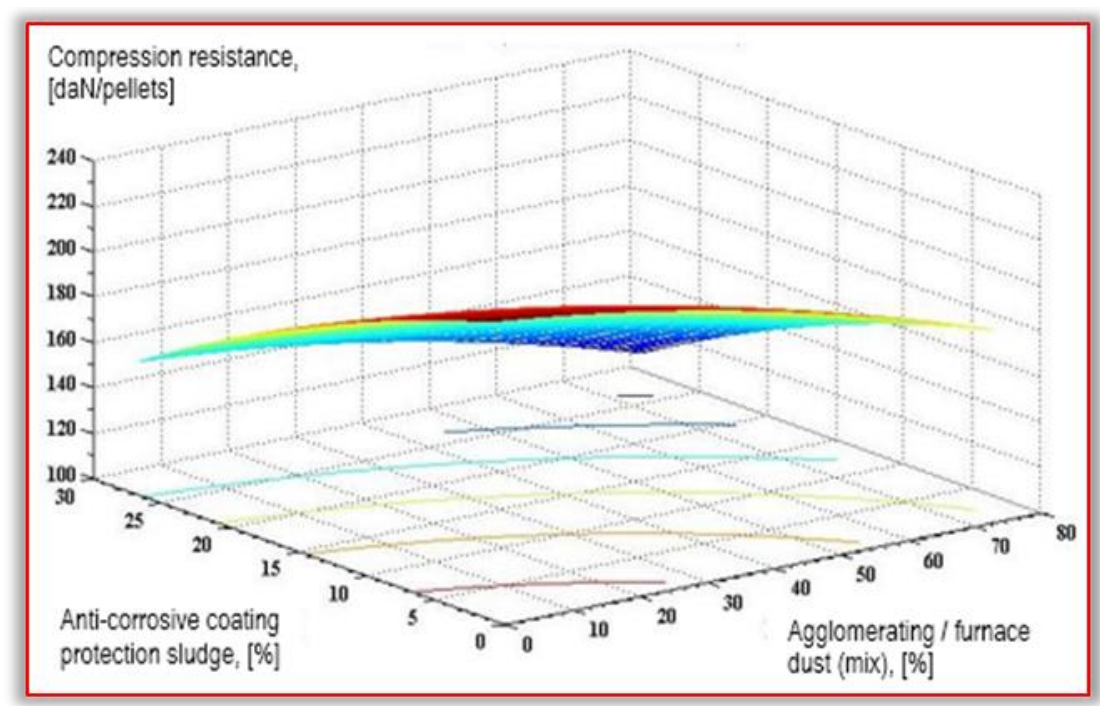

(a) the regression surface described by the laboratory data

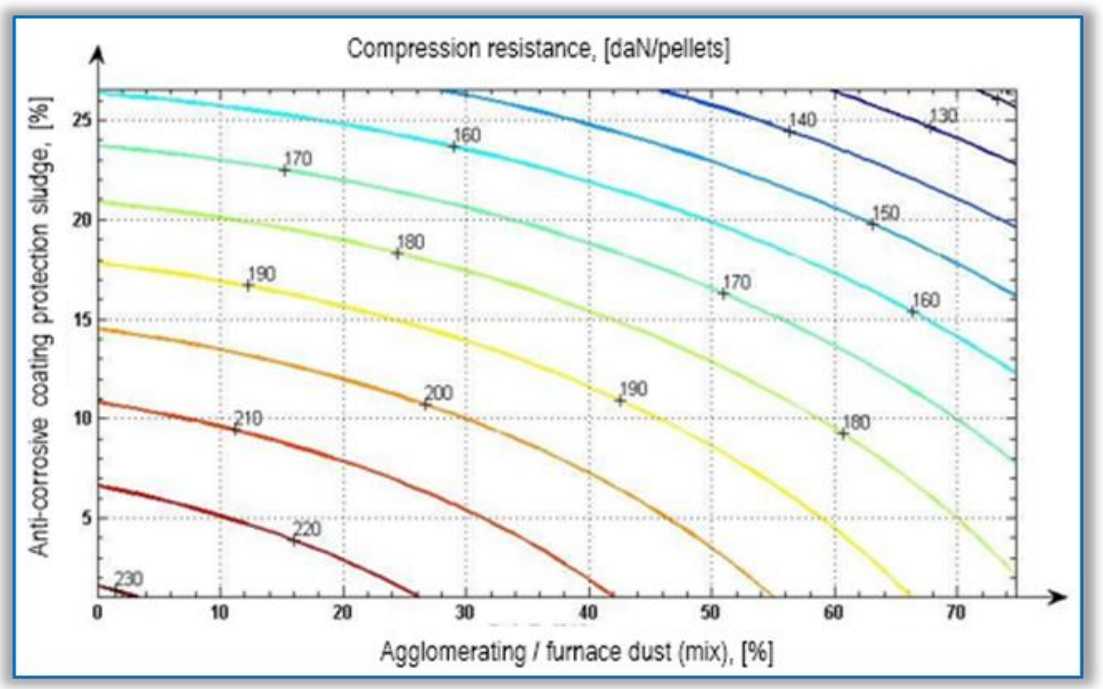

(b) the level curves of compression resistance, in 2D coordinates

Figure 16

Compression resistance of hardened pellets with the proportions of agglomeration-furnace dust and anti-corrosive sludge used in recipes $-[\mathrm{Rc}=\mathrm{f}($ agglomeration-furnace dust, anti-corrosive sludge $)$ ]

Equation type: $z=a_{(1)} x^{2}+a_{(2)} y^{2}+a_{(3)} x y+a_{(4)} x+a_{(5)} y+a_{(6)}$, in which the coefficients are: $\mathrm{a}_{(1)}=-0.0050 ; \mathrm{a}_{(2)}=-0.0430 ; \mathrm{a}_{(3)}=0.0037 ; \mathrm{a}_{(4)}=-0.2944 ; \mathrm{a}_{(5)}=-1.6302 ; \mathrm{a}_{(6)}=232.8057$

Coefficient of multiple correlation: $\mathrm{R}^{2}=0.8742$ (high grade of correlation) 


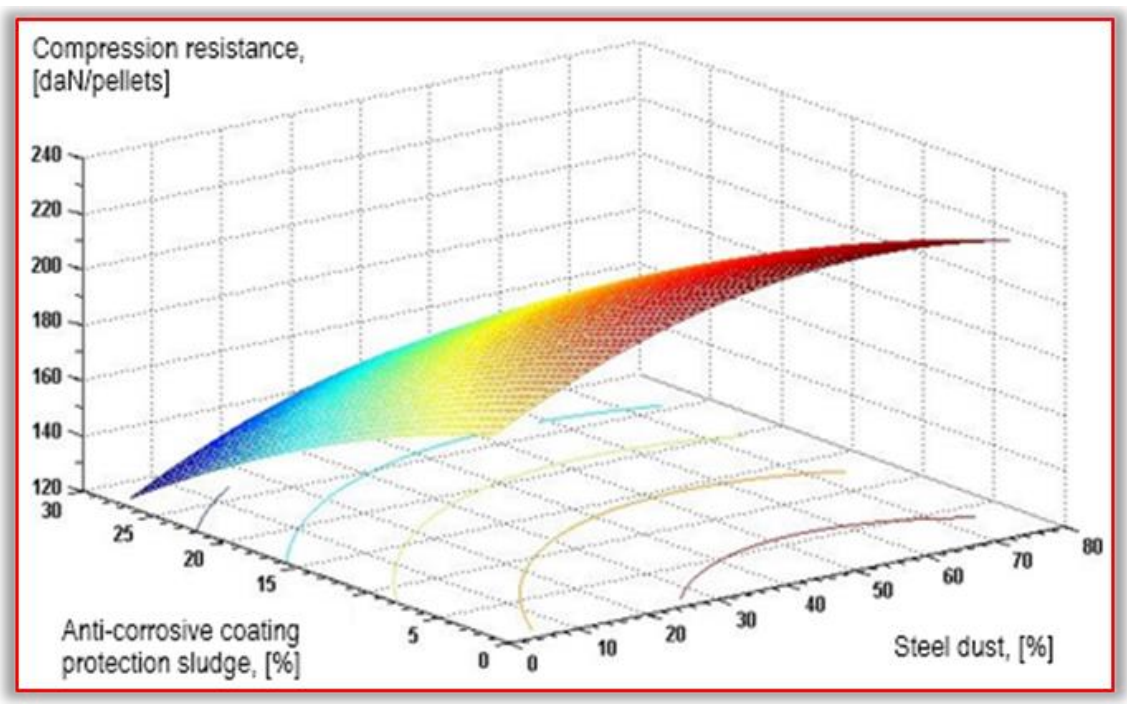

(a) the regression surface described by the laboratory data

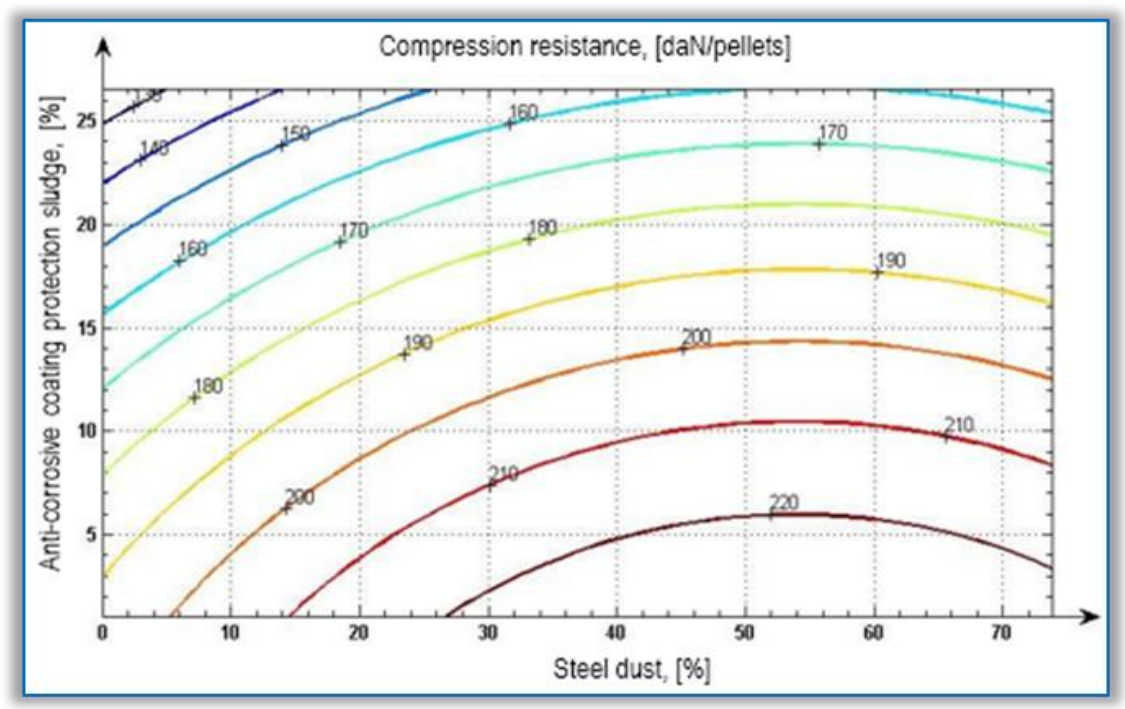

(b) the level curves of compression resistance, in 2D coordinates

Figure 17

Compression resistance of hardened pellet's with the proportions of steel dust and anti-corrosive sludge used in the recipes $-[\mathrm{Rc}=\mathrm{f}($ steel dust, anti-corrosive sludge $)]$

Equation type: $z=a_{(1)} x^{2}+a_{(2)} y^{2}+a_{(3)} x y+a_{(4)} x+a_{(5)} y+a_{(6)}$, in which the coefficients are: $\mathrm{a}_{(1)}=-0.0124 ; \mathrm{a}_{(2)}=-0.0420 ; \mathrm{a}_{(3)}=0.0007 ; \mathrm{a}_{(4)}=1.3304 ; \mathrm{a}_{(5)}=-1.5737 ; \mathrm{a}_{(6)}=194.9876$ Coefficient of multiple correlation: $\mathrm{R}^{2}=0.8967$ (high grade of correlation) 
The increase in the proportion of steel dust to $30-70 \%$ of the pelletizing charge has a positive influence on the resistance to compression of the pellets, but the anticorrosive sludge have a negative influence at increases in quantities, preferably a use of only $5-10 \%$, as is presented in the Figure 17 [ Rc $=f($ steel dust, anti-corrosive sludge)].

Our analysis on the compression resistance of the pellets provided by the additions (bentonite, lime and graphite) are graphically represented in Figures 18-20, based on the results obtained in our experiments. Also, we shows the lime dependence with the two main components (steel dust and agglomeration-furnace dust), in Figure $21[R c=f($ steel dust, lime $)]$ and Figure $22[R c=f($ agglomeration-furnace dust, lime)]. With regard to these cases of analysis, the following technological remarks are required:

- Increasing the proportion of water to $4-6 \%$ and bentonite to about $9 \%$ leads to an increase in compression resistance, as appropriate conditions have been provided to obtain "green" pellets with high strength, from powdery materials, which is also found in the burned pellets (Figure $18[\mathrm{Rc}=\mathrm{f}$ (water, bentonite)]).

- The proportions of the water and lime additions of are well correlated in most cases, with the exception of the addition of lime below $1 \%$ and water below $4 \%$, respectively the addition of lime above $5-6 \%$, where the compression resistance is below the required limit. The field of work is very extensive, virtually unlimited, and from this point of view there are no particular problems (Figure $19[\mathrm{Rc}=\mathrm{f}($ water, lime $)]$ ).

The proportions of lime and bentonite are well chosen, so that they have close influence and can substitute each other, ensuring for compression resistance values $>180 \mathrm{daN} /$ pellet (Figure 20 [Rc $=\mathrm{f}($ lime, bentonite) $]$ ).

The addition of graphite is insignificant, and the quantity used in recipes, does not influence the process of pelletization nor the quality of the burned pellet. For this reason, graphic dependencies are not shown among these results.

Increased resistance to compression of the pellets, slightly decreases with the increase in the proportion of agglomeration-furnace dust and instead increases with the addition of lime, according to the Figure 21 [ $\mathrm{Rc}=\mathrm{f}$ (agglomeration-furnace dust, lime)]. The agglomeration-furnace dust also has a positive effect, in that, in the combustion process, it ensures the reduction of iron oxides, increasing the degree of metalization of the pellets.

Finally, the chart presented in Figure $22[\mathrm{Rc}=\mathrm{f}($ steel dust, lime)] shows that, in terms of the correlation of steel dust and the addition of lime, practically regardless of their proportion and the limits of the addition of lime, up to $6 \%$, consistent pellets are obtained for use in steelmaking aggregates. 


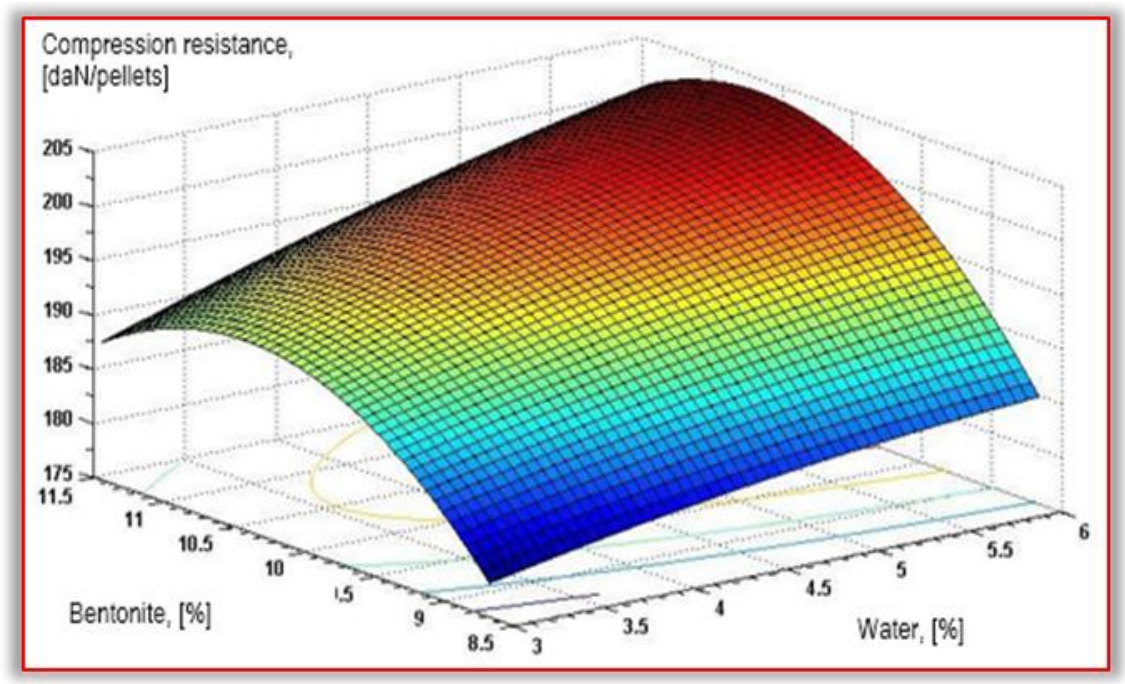

(a) the regression surface described by the laboratory data

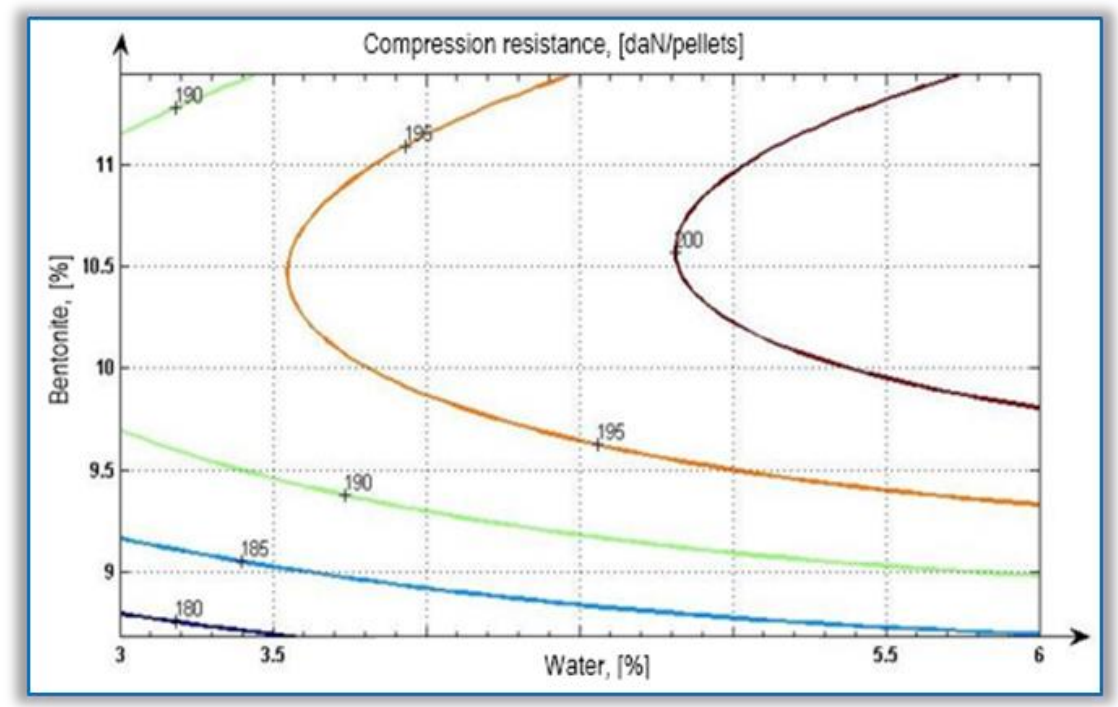

(b) the level curves of compression resistance, in 2D coordinates

Figure 18

Compression resistance of hardened pellet's with the proportions of bentonite and water used in the experimental recipes $-[\mathrm{Rc}=\mathrm{f}($ bentonite, water $)]$

Equation type: $z=a_{(1)} x^{2}+a_{(2)} y^{2}+a_{(3)} x y+a_{(4)} x+a_{(5)} y+a_{(6)}$, in which the coefficients are: $\mathrm{a}_{(1)}=-0.4072 ; \mathrm{a}_{(2)}=-1.1150 ; \mathrm{a}_{(3)}=-4.7305 ; \mathrm{a}_{(4)}=0.8048 ; \mathrm{a}_{(5)}=96.2018 ; \mathrm{a}_{(6)}=-314.4748$

Coefficient of multiple correlation: $\mathrm{R}^{2}=0.7922$ (high grade of correlation) 


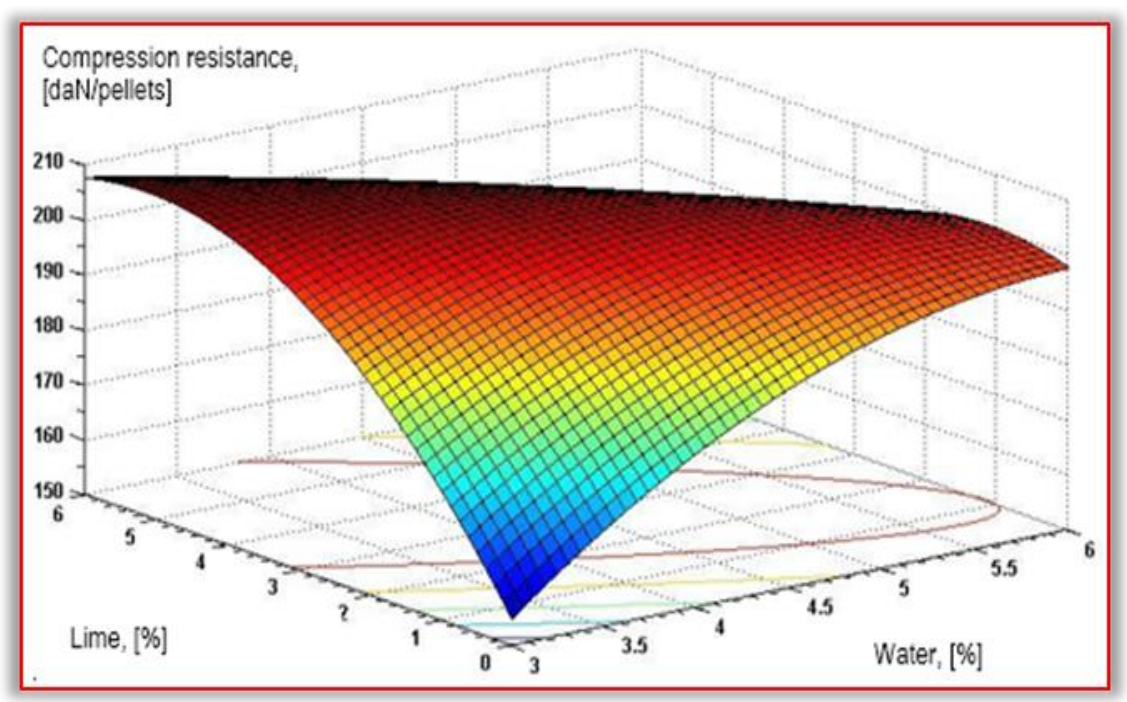

(a) the regression surface described by the laboratory data

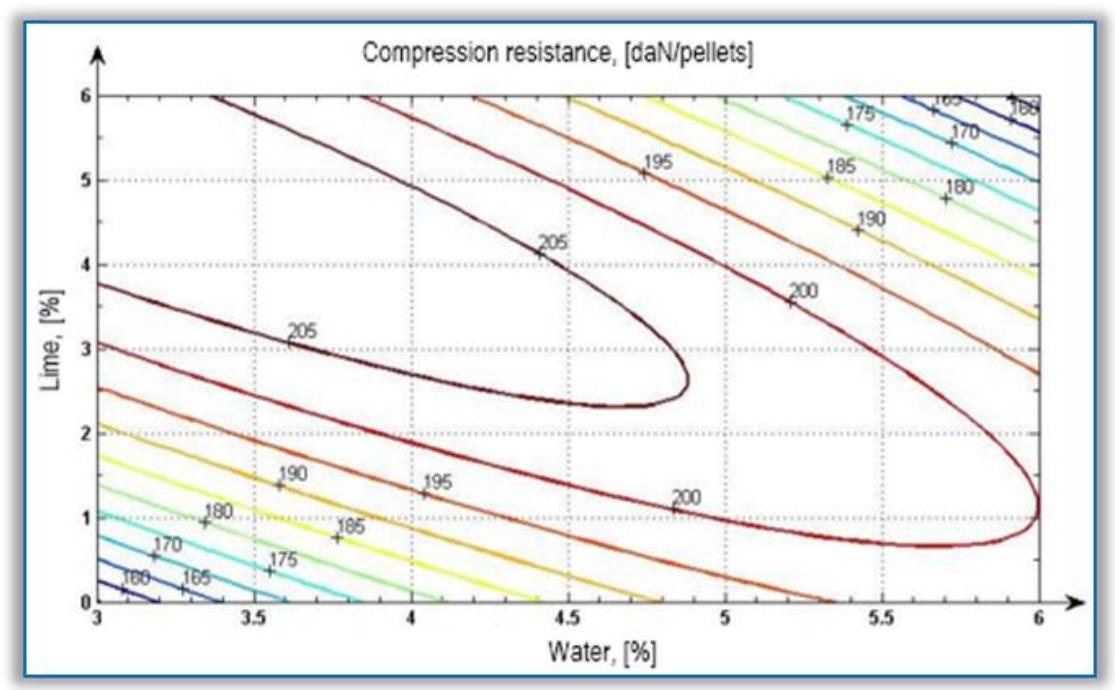

(b) the level curves of compression resistance, in 2D coordinates

Figure 19

Compression resistance of hardened pellet's with the proportions of lime and water used in the experimental recipes $-[\mathrm{Rc}=\mathrm{f}($ lime, water $)]$

Equation type: $z=a_{(1)} x^{2}+a_{(2)} y^{2}+a_{(3)} x y+a_{(4)} x+a_{(5)} y+a_{(6)}$, in which the coefficients are: $\mathrm{a}_{(1)}=-4.4814 ; \mathrm{a}_{(2)}=-2.0376 ; \mathrm{a}_{(3)}=-5.4652 ; \mathrm{a}_{(4)}=54.5467 ; \mathrm{a}_{(5)}=37.3916 ; \mathrm{a}_{(6)}=31.4430$

Coefficient of multiple correlation: $\mathrm{R}^{2}=0.6056$ (relative high grade of correlation) 


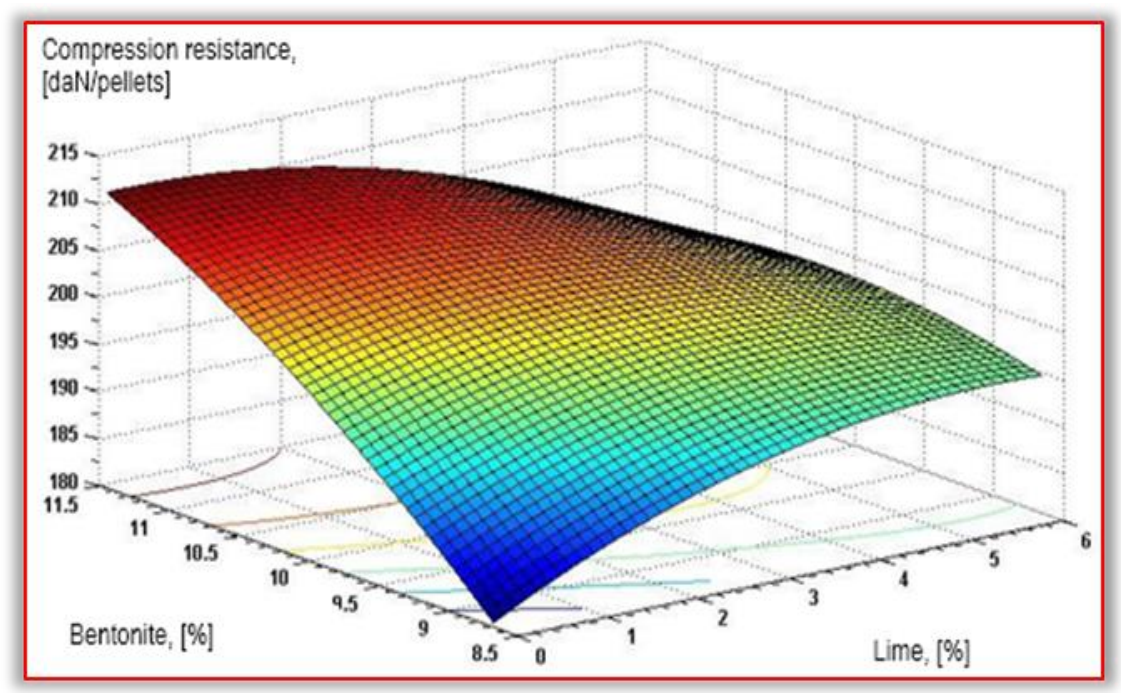

(a) the regression surface described by the laboratory data

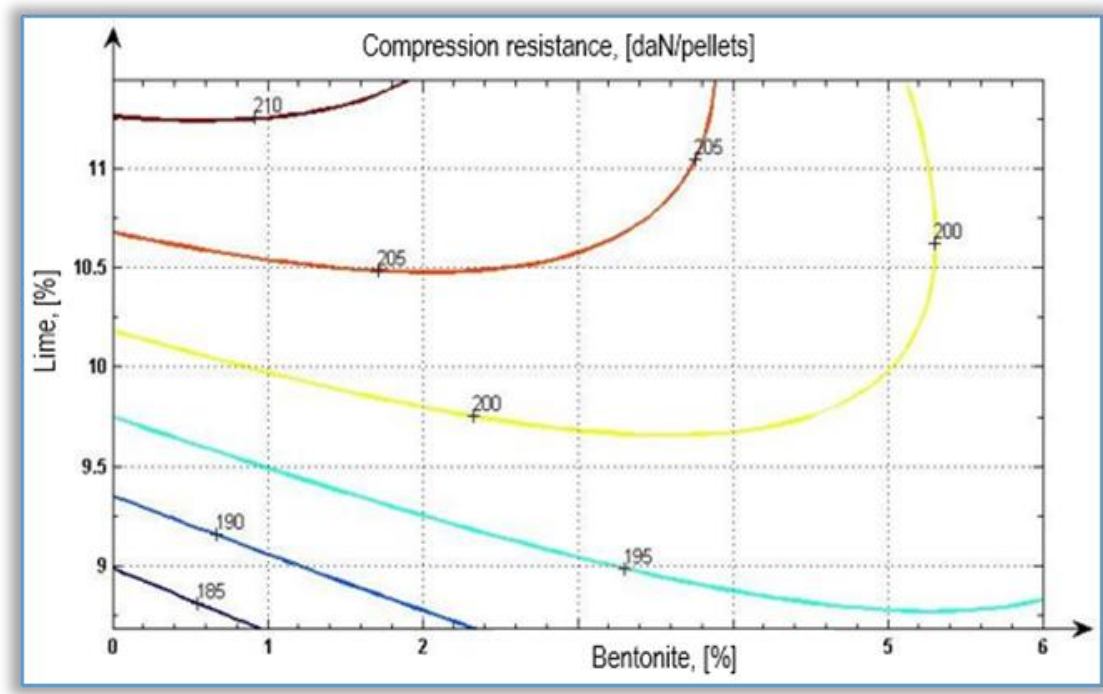

(b) the level curves of compression resistance, in 2D coordinates

Figure 20

Compression resistance of hardened pellet's with the proportions of lime and bentonite used in the experimental recipes $-[\mathrm{Rc}=\mathrm{f}($ lime, bentonite $)]$

Equation type: $z=a_{(1)} x^{2}+a_{(2)} y^{2}+a_{(3)} x y+a_{(4)} x+a_{(5)} y+a_{(6)}$, in which the coefficients are: $\mathrm{a}_{(1)}=-0.4720 ; \mathrm{a}_{(2)}=-1.4200 ; \mathrm{a}_{(3)}=-1.7941 ; \mathrm{a}_{(4)}=20.7279 ; \mathrm{a}_{(5)}=39.7588 ; \mathrm{a}_{(6)}=-57.6807$ Coefficient of multiple correlation: $\mathrm{R}^{2}=0.8698$ (high grade of correlation) 


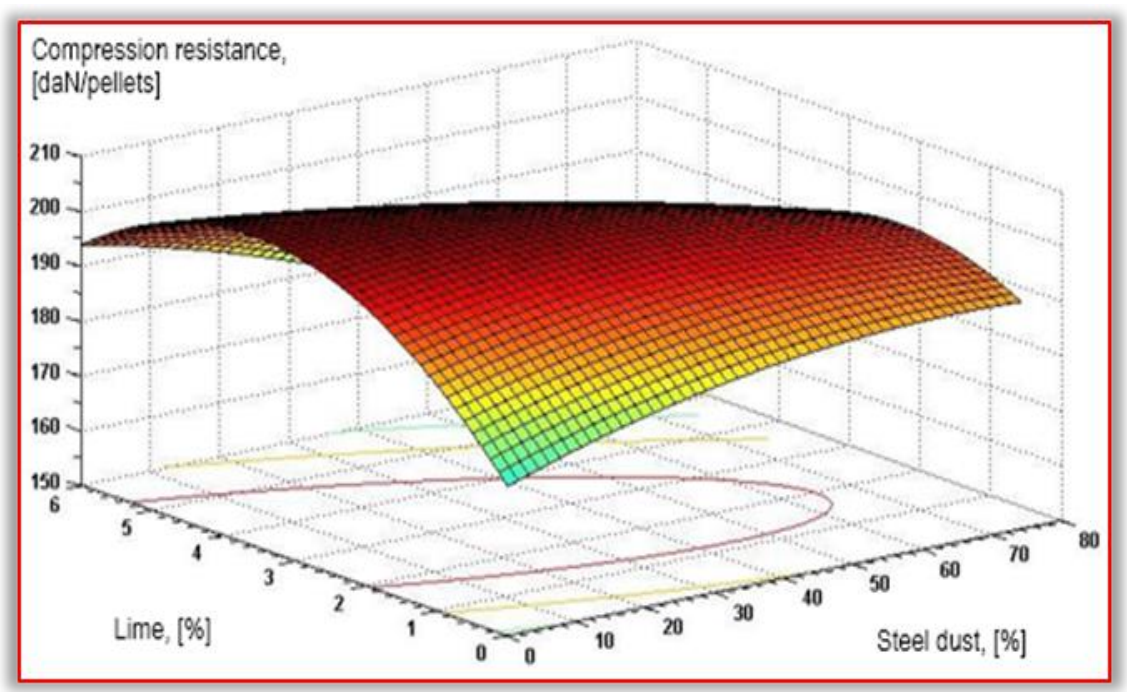

(a) the regression surface described by the laboratory data

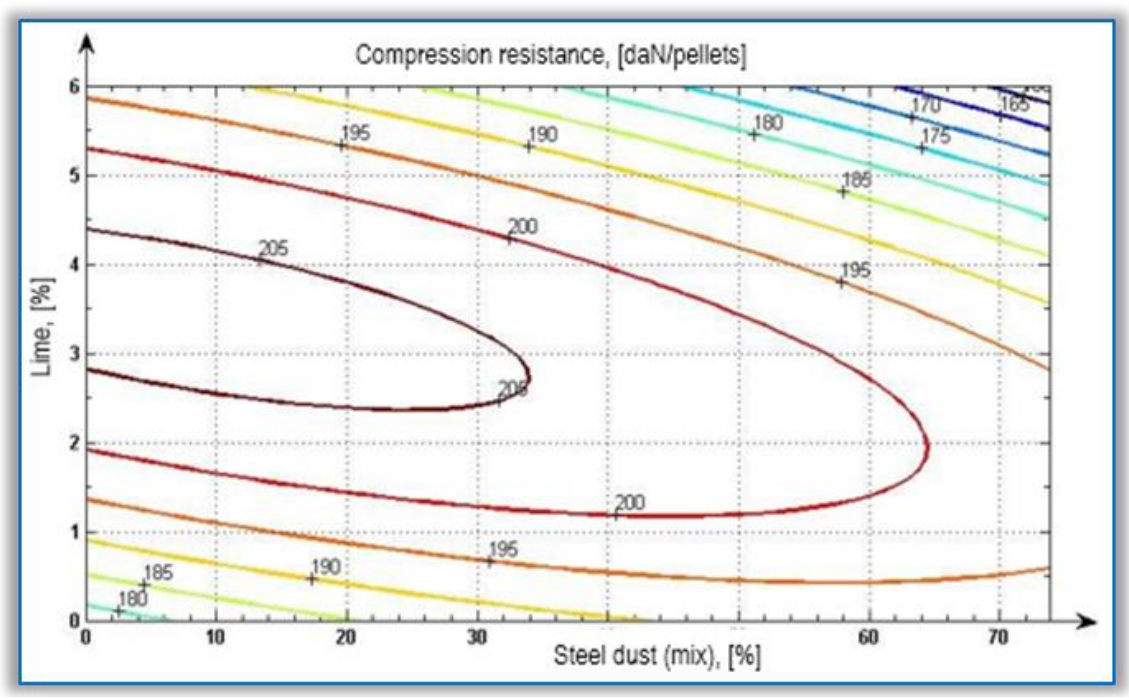

(b) the level curves of compression resistance, in $2 \mathrm{D}$ coordinates

Figure 21

Compression resistance of hardened pellet's with the proportions of steel dust and lime used in the experimental recipes $-[R c=f($ steel dust, lime $)]$

Equation type: $z=a_{(1)} x^{2}+a_{(2)} y^{2}+a_{(3)} x y+a_{(4)} x+a_{(5)} y+a_{(6)}$, in which the coefficients are: $\mathrm{a}_{(1)}=-0.0012 ; \mathrm{a}_{(2)}=-0.6413 ; \mathrm{a}_{(3)}=-0.0085 ; \mathrm{a}_{(4)}=-0.1783 ; \mathrm{a}_{(5)}=6.9270 ; \mathrm{a}_{(6)}=191.1665$ Coefficient of multiple correlation: $\mathrm{R}^{2}=0.7759$ (high grade of correlation) 


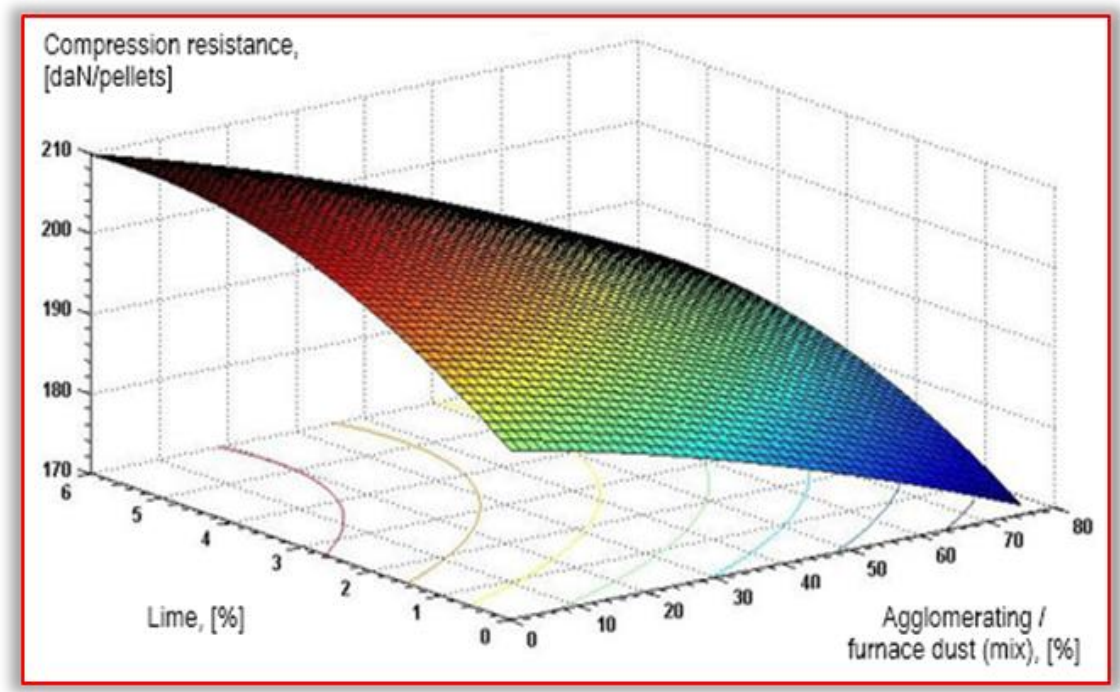

(a) the regression surface described by the laboratory data

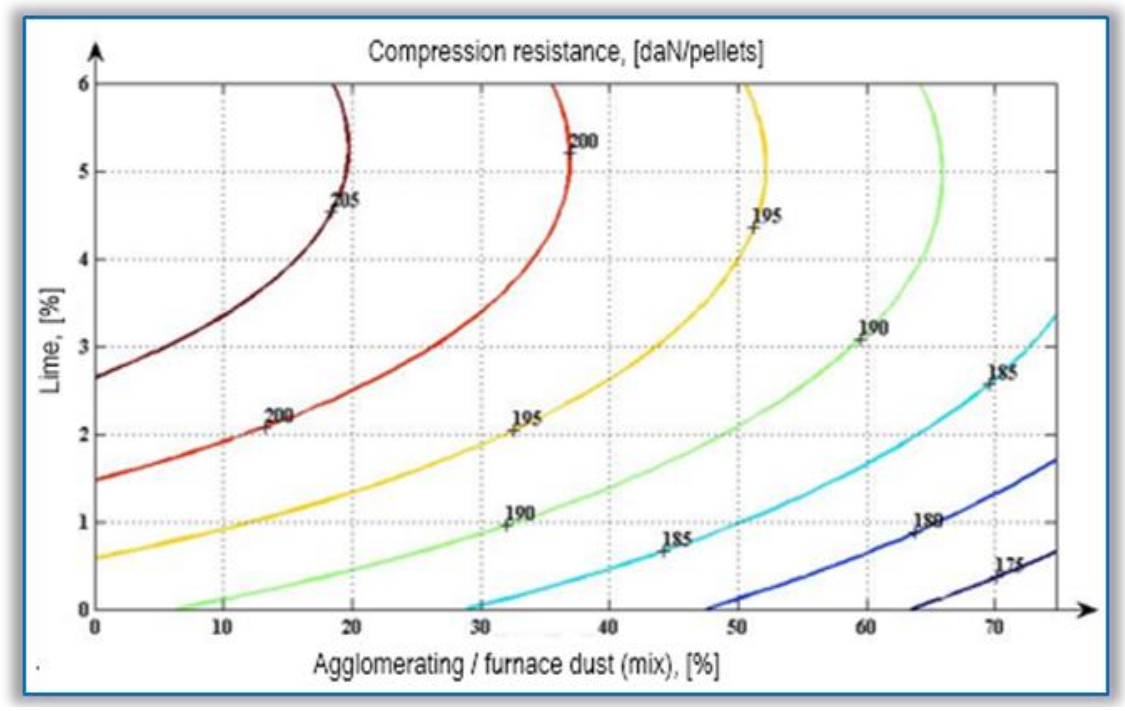

(b) the level curves of compression resistance, in 2D coordinates

Figure 22

Compression resistance of hardened pellet's with the proportions of agglomeration-furnace dust and lime used in the experimental recipes $-[\mathrm{Rc}=\mathrm{f}($ agglomeration-furnace dust, lime $)]$

Equation type: $z=a_{(1)} x^{2}+a_{(2)} y^{2}+a_{(3)} x y+a_{(4)} x+a_{(5)} y+a_{(6)}$, in which the coefficients are: $\mathrm{a}_{(1)}=-0.0034 ; \mathrm{a}_{(2)}=-2.2408 ; \mathrm{a}_{(3)}=-0.1161 ; \mathrm{a}_{(4)}=0.4437 ; \mathrm{a}_{(5)}=16.1699 ; \mathrm{a}_{(6)}=177.2020$ Coefficient of multiple correlation: $\mathrm{R}^{2}=0.8171$ (high grade of correlation) 


\section{Conclusions}

In this paper the research and relevant results are presented, in regard to the formation of pellets, using waste from ferrous industry (steel dust, agglomeratingfurnace dust) and mining and mineral processing sectors (red mud/bauxide residue, anti-corrosive sludge). For this, we considered the existing ferrous powdery waste in the Hunedoara County (Hunedoara and Calan) area and several powdery wastes from Bihor County (Oradea) area. In addition, within the pellets recipes, graphite is used, as the reducing agent and respectively, bentonite and lime are used as binders.

Our research work has considered the following technological problems:

- The wetting capacity of processed materials, in the pelletizor scale

- The quality of "green" pellets according to the processed materials, their chemical composition and granulation, the addition of water and binders

- The quality of the hardened pellets according to the processed solid materials, the chemical composition and their obtained dimensions, the addition of water and the binders quantity

- The compression resistance of the burned pellets according to the solid materials processed, the addition of water and binders

On the basis of the above, we studied the possibilities of recovery of powdery ferrous waste in the steel industry. Given that at the national level, this activity, unfortunately, has a very limited scope. Our strategies should focus on development of recycling/valorisation capacities of iron containing raw materials contained in waste, as well as on installations and technologies using waste in the production process. In this sense, analyzing the results obtained in our laboratory, it follows that various waste processed in the form of pellets, according to the experimental recipes \#1-6, can be further utilized in industrial applications.

\section{Acknowledgment}

The study was carried out on the basis of extensive research over the last 20 years, undertaken within the Hunedoara Faculty of Engineering, following the results of numerous researches $[7,9,10,13-26]$ that concerned a large number of researchers in this institution. This research presented now is part of the research on the doctoral thesis [13], as well as a number of researches undertaken after this period in order to recover by pelletization of materials containing valuable or deficitary elements from different kinds of powdery waste stored in areas with risk factor.

\section{References}

[1] Romanian Government, Romania's Sustainable Development Strategy 2030 - Implementing the 2030 Agenda for Sustainable Development, Department of Sustainable Development (2018) http://dezvoltaredurabila.gov.ro/ 
[2] European Commission, The Environmental Implementation Review 2019 Country Report: Romania, Directorate-General for Environment (2019)

[3] Blengini, G. A., Mathieux, F., Mancini, L., Nyberg, M., Viegas, H. M., Recovery of critical and other raw materials from mining waste and landfills - State of play on existing practices, Luxembourg: Publications Office of the European Union (2019)

[4] Ministry of Environment, Waters and Forests, Romania, National Strategy for the Management of Contaminated Sites (2015) http://www.mmediu.ro

[5] National Environmental Protection Agency, Present status for Soil Rehabilitation in Romania - Priorities, Workshop on Contaminated site caracterisation, $7^{\text {th }}$ Framework Programme Theme 6 "Environment", Soil and Subsoil Protection Office (2013)

[6] Romanian Government, National Strategy and National Plan for the management of contaminated sites in Romania. Chapter III: Current situation of potentially contaminated/contaminated sites in Romania (2013)

[7] T. Heput, E. Ardelean, N. Constantin, A. Socalici, M. Ardelean, R. Buzduga, Recovery of small and powder ferrous waste, Politehnica Publishing House, Timisoara, (2011) pp. 7-11

[8] H. W. Campbell, Sludge management-future issues and trends, Water science and technology, 41(8), (2000) pp. 1-8

[9] I. Butnariu, N. Constantin, C. Dobrescu, T. Heput, Research on the recycling of pulverulent waste from the ferrous and non-ferrous industry in order tu reduced the pollution. Revista de Chimie, 69(5) (2018) pp. 10661070

[10] V. A Socalici, Contribution on improvement the quality of steel, University Politehnica Timisoara (2016) habilitation thesis

[11] F. Su, H. O. Lampinen, R. Robinson, Recycling of sludge and dust to the BOF converter by cold bonded pelletizing, ISIJ international, 44(4) (2004) pp. $770-776$

[12] S. Kumar, R. Kumar, A. Bandopadhyay, Innovative methodologies for the utilisation of wastes from metallurgical and allied industries, Resources, Conservation and Recycling, 48(4), (2006) pp. 301-314

[13] S. Serban, Research on waste recovery containing iron and steel alloying elements, University Politehnica Timisoara, (2015) doctoral thesis

[14] T. Heput, A. Socalici, E. Ardelean, M. Ardelean, Environment ecological process in Hunedoara area through reinsertion in economic circuit of scrap and pulverous waste. Annals of the Faculty of Engineering Hunedoara Journal of Engineering, VII(3) (2009) pp. 293-298 
[15] T. Hepuţ, I. Kiss, V. Puţan, Researches regarding the implementation in the industrial practices of the accounting technologies of the ferrous pulverous wastes, stored in the regional ponds, Annals of the Faculty of Engineering Hunedoara, 1(2) (2003) pp. 71-75

[16] S. Serban, T. Heput, I. Kiss, Recycling experiments on pulverous wastes resulted from ferrous industry, mining and energetic sectors, Acta Technica Corviniensis - Bulletin of Engineering, X, 2, (2017) pp. 139-146

[17] S. Serban, T. Heput, Ferrous wastes recovery possibilities in the area of steel industry - experiments in the laboratory phase on the briquettes production from fine and pulverous wastes, Acta Technica Corviniensis Bulletin of Engineering, VIII, 3, (2015), pp. 49-56

[18] S. Serban, T. Heput, I. Kiss, Recovery possibilities through pelletizing of the pulverous wastes stored in the regional ponds, VIth International Conference Industrial Engineering \& Environmental Protection (IIZS 2016), Zrenjanin, Serbia, 2016, pp. 116-121

[19] S. Serban, Reintroduction of iron-containing waste and steel alloying elements into the economic circuit, Acta Technica Corviniensis - Bulletin of Engineering, XI, 4, (2018), pp. 127-134

[20] M. L. Strugariu, T. Heput, A. Socalici, Recovery of sludge resulting from corrosion protection operations, Metalurgia International, 18(8) (2013), pp. $161-166$

[21] A. V. Socalici, E. Ardelean, M. L. Strugariu, Research on sustainable use of powdery waste, Environmental Engineering and Management Journal (EEMJ), 15(1) (2016) pp. 207-212

[22] D. A. Popescu, Study on the quality of industrial waste deposited in ponds, Annals of Faculty of Engineering Hunedoara - International Journal of Engineering, XII, 4 (2014), pp. 315-321

[23] D. A. Popescu, Research into the recovery of pulverous and small waste from the metallurgical industry, University Politehnica Timisoara (2018) doctoral thesis

[24] A. S. Todoruţ, Management research and recovery of small and powdery wastes, resulted from materials industry, for sustainable development of Hunedoara, University Politehnica Timisoara, (2013) doctoral thesis

[25] E. M. Crişan, Research into the recovery of iron and carbon-containing pulverous and small waste in steel, University Politehnica Timisoara, (2018), doctoral thesis

[26] E. M. Crişan, T. Heput, Research on the influence of basic additives on the compressive strength of pellets. Annals of Faculty of Engineering Hunedoara - International Journal of Engineering, 9(3) (2011) pp. 449454 